\title{
KONTRIBUSI KOMPOSISI VEGETASI DALAM PENYIMPANAN DAN SERAPAN KARBON DI HUTAN RAKYAT DESA NEGARA RATU II KECAMATAN NATAR KABUPATEN LAMPUNG SELATAN
}

\author{
Contribution of Vegetation's Compotition in Carbon Storage and Uptake in Private Forest of \\ Negara Ratu II Village Natar District South Lampung Regency

\section{Dian Afriansyah ${ }^{\star}$, Duryat dan Hari Kaskoyo} \\ Jurusan Kehutanan, Fakultas Pertanian, Universitas Lampung \\ Jl. Prof. Dr. Soemantri Brojonegoro No. 1, Bandar Lampung \\ "Email : dianafriansyah62@gmail.com
}

\begin{abstract}
Tree stands in community forest have potential to absorb carbon in the air by storing in the body parts of the tree. This study aims to determine the effect of community forest's stand types on the amount of reserves and carbon uptake. The sampling method used is the cluster sampling method to determine the sample. Biomass data are collection destructive and non destructive methods. Estimation of biomass is carried out using the allometric equations. Measurement of carbon content using the formula from BSN (2011) x 0.47. Comparative analysis of carbon reserves and removals uptake using the variance test and $5 \%$ BNT test. Public forests in the Negara Ratu II village with gold teak stands have carbon reserves and removals (135.87 tons/ha and 499,00 ton/ha). the most significant compared to community forests with other types of stands. While the reserve value and carbon uptake between white teak (44.86 tons/ha and 164.63 tons/ha), acacia (54.13 tons/ha and 191.20 tons/ ha), red jabon (51.20ton/ha and 187.90 tons/ha), white jabon (59.51 tons/ha and 218.40 tons/ha), is no different.
\end{abstract}

Key words: Carbon Stock, Village of Negara Ratu II, Private Forest.

\section{ABSTRAK}

Tegakan pohon di hutan rakyat berpotensi untuk menyerap karbon di udara dengan menyimpan pada bagian-bagian tanaman. Penelitian ini bertujuan untuk mengetahui pengaruh tipe tegakan hutan rakyat terhadap jumlah cadangan dan serapan karbonnya. Metode sampling yang digunakan adalah metode cluster sampling karna terdapat 5 tipe hutan berdasarkan jenis tanaman. Pengumpulan data biomassa menggunakan metode destruktif dan non destruktif. Pendugaan biomassa dilakukan dengan menggunakan persamaan allometrik. Pengukuran kandungan karbon menggunakan rumus dari BSN (2011) biomassa $x$ 0,47. Analisis perbandingan cadangan dan serapan karbon dilakukan menggunakan uji sidik ragam dan uji BNT pada taraf $5 \%$. Hutan rakyat di Desa Negara Ratu II dengan tegakan jati emas memiliki cadangan dan serapan karbon (135,87 ton/ha dan 499,00 ton/ha) paling nyata tertinggi dibandingkan dengan hutan rakyat dengan tipe tegakan lain. Sedangkan nilai cadangan dan serapan karbon antara jati putih $(44,86$ ton/ha dan 164,63 ton/ha), akasia $(54,13$ ton/ha dan 191,20 ton/ha), jabon merah $(51,20$ ton/ha dan 187,90 ton/ha), jabon putih $(59,51$ ton/ha dan 218,40 ton/ha). Tegakan jati emas memiliki cadangan da serapan karbon lebih tinggi 
Jurnal Belantara Vol. 2, No. 2, Agustus 2019 (112-118)

dibandingkan dengan tipe hutan yang lain. Sedangkan tipe hutan jati putih, akasia, jabon merah dan jabon putih memiliki cadangan dan serapan karbon yang sama besar.

Kata kunci: Cadangan Karbon, Desa Negara Ratu II, Hutan Rakyat.

\section{PENDAHULUAN}

Suhu permukaan bumi telah mengalami kenaikan yang disebabkan oleh pemanasan global. Tim Arupa (2014) menyatakan bahwa pemanasan global merupakan proses meningkatnya suhu rata-rata global, yang meliputi atmosfer dan permukaan bumi. Peningkatan konsentrasi gas rumah kaca (GRK) di atmosfer telah dipercepat oleh kegiatan manusia seperti pembakaran bahan bakar fosil dan deforestasi (IPCC, 2006). Salah satu cara untuk mengurangi konsentrasi GRK khususnya $\mathrm{CO}_{2}$ di atmosfer adalah dengan menyerap dan menyimpan karbon di dalam biomassa tumbuhan.

Hutan rakyat dengan keragaman penyusun tegakan diharapkan mampu meningkatkan cadangan serapan karbon ditengah rusaknya kondisi hutan di Provinsi Lampung. Laju kerusakan hutan akibat deforestasi, kebakaran, dan degradasi di Provinsi Lampung sudah mencapai 65,47\% (Dinas Kehutanan Provinsi Lampung, 2013). Dalam mitigasi perubahan iklim, hutan rakyat diharapkan mampu memberi kontribusi dalam penurunan gas rumah kaca nasional secara signifikan (Rochmayanto, 2012).

Aspek pemilihan jenis merupakan salah satu cara pengelolaan hutan untuk meningkatkan manfaat ekologis yang dapat mengatasi beberapa permasalahan lingkungan yang langsung dirasakan oleh petani (Kaskoyo et.al, 2017). Jumlah cadangan dan serapan karbon dapat menjadi acuan seberapa besar jenis penyusun tegakan hutan tersebut dalam memberikan manfaat ekologi. Penelitian ini bertujuan untuk mengetahui seberapa besar pengaruh tipe penyusun tegakan hutan terhadap jumlah cadangan dan serapan karbon di hutan rakyat.

\section{METODE}

\section{A. Lokasi dan Waktu Penelitian}

Penelitian ini dilaksanakan di hutan rakyat Desa Negara Ratu II Kecamatan Natar Kabupaten Lampung Selatan pada bulan Januari-Februari 2018. Data yang dikumpulkan untuk pendugaan biomassa yaitu sebagai berikut :

1. Jenis pohon, tinggi pohon dan diameter pohon pada semua fase (semai, pancang, tiang dan pohon) untuk pengukuran biomassa.

2. Jenis nekromassa, tinggi / panjang nekromassa, diameter nekromassa dan tingkat keutuhan nekromassa untuk pengukuran nekromassa.

3. Berat basah serasah, berat basah contoh serasah dan berat kering contoh serasah untuk pengukuran biomassa serasah.

4. Berat basah tumbuhan bawah, berat basah contoh tumbuhan bawah dan berat kering contoh tumbuhan bawah untuk pengukuran biomassa tumbuhan bawah.

Penarikan sampel dilakukan secara cluster sampling yaitu pengambilan sampel data yang dilakukan dengan cara mengelompokkan sampel berdasarkan jenis tegakannya. Penelitian dilakukan dengan metode rancangan acak kelompok (RAK) dengan 5 jenis biomassa pada masing-masing kelompok tegakan, yaitu : jati putih, jati emas, akasia, jabon merah dan jabon putih. Jenis biomassa yang akan diambil antara lain : semai, pancang, tiang 
dan pohon, nekromassa, serasah dan tumbuhan bawah. Masing-masing jenis biomasa diambil dari 5 sampel plot pengamatan.

\section{B. Analisis Data}

\section{Biomassa pohon dan nekromassa}

Kandungan biomassa pohon dan nekromassa diperoleh dengan menggunakan persamaan allometrik (Tabel 1). Pengukuran nekromassa dilakukan terhadap pohon roboh, kayu atau batang tumbang yang sudah mati. Diameternya tetap diukur dan diestimasi sama dengan estimasi biomassa pohon hidup, hanya nilai persamaan allometrik dan berat jenisnya yang berbeda.

Tabel 1. Model persamaan allometrik yang digunakan

Table 1. Allometric equation model used

\begin{tabular}{lll}
\hline No & Jenis Tegakan & Persamaan Allometrik \\
\hline 1 & Jati Putih & $\mathrm{BK}=0,015(\mathrm{D})^{0,08}$ \\
2 & Jati Emas & $\mathrm{BK}=0,015(\mathrm{D})^{1,08}$ \\
3 & Akasia & $\mathrm{BK}=0,077(\mathrm{D})^{0.90}$ \\
4 & Jabon Merah & $\mathrm{BK}=0,11(\mathrm{D})^{2.62}$ \\
5 & Jabon Putih & $\mathrm{BK}=0,11(\mathrm{D})^{2.62}$ \\
6 & Pohon-pohon bercabang ${ }^{\star *}$ & $\mathrm{BK}=0,11 \rho(\mathrm{D})^{2,62}$ \\
7 & Pohon tidak bercabang $^{\star *}$ & $\mathrm{BK}=\pi \rho \mathrm{D}^{2} \mathrm{H} / 40$ \\
\hline
\end{tabular}

Keterangan :

BK : Berat Kering

Sumber: * = Nugroho, (2014).

** = Hairiah dan Subekti, (2007).

\section{Biomassa seresah dan tumbuhan bawah}

Rumus Biomass Expansion Factor (Brown, 1997) digunakan untuk mengetahui kandungan biomassa serasah dan tumbuhan bawah.

$$
\text { Total BK }=\frac{\text { BK sub contoh }(\mathrm{g})}{\mathrm{BB} \text { sub contoh }(\mathrm{g})} x \text { total BB }(\mathrm{g})
$$

$\mathrm{BK}=$ Berat Kering

$\mathrm{BB}=$ Berat Basah 


\section{Kesesuaian Cadangan Karbon Berdasarkan IPCC (2006)}

Penghitungan karbon menggunakan rumus dari SNI (BSN, 2011). Hutan yang baik adalah hutan yang memiliki cadangan karbon rata-rata > 135 ton/ha berdasarkan Intergovernmental Panel on Climate Change (IPCC, 2006).

$$
C=\text { Biomassa } \times 47 \%
$$

$\mathrm{C}=$ Karbon

\section{Penghitungan Cadangan Karbon per Hektar pada Tiap Plot}

Penghitungan cadangan karbon perhektar dilakukan pada semua objek pengukuran biomassa menggunakan rumus dari SNI (BSN, 2011) berikut.

$$
\begin{array}{ll}
\qquad C n=\frac{C x}{1000} \times \frac{10000}{\text { luas plot }} \\
\text { Cn } & =\text { kandungan karbon perhektar masing-masing objek (ton/ha) } \\
\text { C } & =\text { kandungan karbon masing-masing objek }(\mathrm{kg}) \\
\text { Luas plot } & =\text { luas plot pada masing-masing objek }\left(\mathrm{m}^{2}\right)
\end{array}
$$

\section{Penyerapan $\mathrm{CO}_{2}$}

Serapan $\mathrm{CO}_{2}$ diperoleh dengan menggunakan rumus Hardjana (2010).

$$
\mathrm{WCO}_{2}=\mathrm{W}_{\mathrm{tc}} \times 3,67
$$

Keterangan:

$\mathrm{WCO}_{2} \quad=$ banyaknya $\mathrm{CO}_{2}$ yang diserap (ton);

$\mathrm{W}_{\mathrm{tc}} \quad=$ berat total unsur karbon tegakan jenis dan umur tertentu (ton/ha);

$3,67=$ angka ekivalen/konversi unsur karbon $(\mathrm{C}) \mathrm{ke} \mathrm{CO}_{2}$ [massa atom $\mathrm{C}=1$ dan $\mathrm{O}=16$, $\mathrm{CO}_{2}=(1 \times 12)+(2 \times 16)=44 ;$ konversinya $\left.=>(44: 12)=3,67\right]$.

\section{Perbandingan Cadangan dan Serapan Karbon pada masing-masing Perlakuan}

Nilai perbandingan cadangan dan serapan karbon diketahui dengan menggunakan Rancangan Acak Kelompok (Hanafiah, 2011). Kelima perlakuan (jenis tegakan) selanjutnya di uji Beda Nyata Taraf (BNT) 5\%.

\section{HASIL dan PEMBAHASAN}

\section{Total Karbon Tersimpan dalam Keseluruhan Plot}

Cadangan karbon dari tiap jenis penyusun tegakan di hutan rakyat Desa Negara Ratu II disajikan pada Tabel 2. 
Tabel 2. Rekapitulasi perhitungan kandungan biomassa dari masing-masing objek pengamatan di hutan rakyat Desa Negara Ratu II.

Table 2. The Recapitulation of biomass calculation of each research object in private forest of Negara Ratu II Village.

\begin{tabular}{llcccccccc}
\hline \multirow{2}{*}{$\begin{array}{l}\text { Jenis } \\
\text { Tanaman }\end{array}$} & $\mathbf{P}$ & $\mathbf{T}$ & $\mathbf{N}$ & $\mathbf{S}$ & $\mathbf{T B}$ & Total & \multicolumn{2}{c}{$\begin{array}{l}\text { Karbon } \\
\text { Tersimpan Areal Karbon }\end{array}$} \\
\hline Jati Putih & 33.25 & 60.08 & 1.16 & 0.76 & 0.19 & 95.44 & 44.86 & 3 & 134.58 \\
Jati Emas & 145.30 & 142.99 & 0.00 & 0.79 & 0.21 & 289.29 & 135,97 & 8 & $1,087.76$ \\
Akasia & 38.07 & 71.16 & 0.60 & 0.78 & 0.24 & 110.85 & 52.10 & 2 & 104.2 \\
Jabon Merah & 38.15 & 69.91 & 0.00 & 0.65 & 0.22 & 108.93 & 51.20 & 5 & 256 \\
Jabon Putih & 23.64 & 101.89 & 0.10 & 0.78 & 0.21 & 126.62 & 59.51 & 3 & 178.53 \\
\hline Jumlah & 278.40 & 446.04 & 1.86 & 3.77 & 1.07 & 731.13 & 343.63 & 21 & 1,761 \\
\hline Persentase & $38 \%$ & $61 \%$ & $0 \%$ & $1 \%$ & $0 \%$ & $100 \%$ & & & \\
\hline
\end{tabular}

Keterangan :

P : Pohon

T : : Tiang

$\mathrm{N} \quad$ : Nekromassa

S : Seresah

TB : Tumbuhan Bawah

Karbon tersimpan pada hutan rakyat Desa Negara Ratu II memiliki jumlah total 1.761 ton/ha (Tabel 2), sehingga hutan rakyat Desa Negara Ratu II sudah baik dalam penyimpanan cadangan karbon. Berdasarkan IPCC (2006) lahan hutan tanaman yang dikategorikan baik yaitu memiliki kandungan karbon sebesar 138 ton/ha atau lebih. Besarnya simpanan cadangan karbon pada hutan rakyat Desa Negara Ratu II dipengaruhi oleh kerapatan tegakan dan riap diameter pada lokasi penelitian tersebut, karna diameter adalah indikator tinggi rendahnya karbon yang tersimpan. Hal ini diperkuat oleh hasil penelitian yang dilakukan oleh Putri dan Wulandari (2015) yang menyatakan bahwa semakin tinggi kerapatan tegakan dan diameter pada tegakan damar mata kucing di Pekon Gunung Kemala Kecamatan Krui Kabupaten Lampung Barat maka semakin tinggi potensi cadangan karbon.

\section{Perbandingan Cadangan dan Serapan Karbon Pada Berbagai Tipe Tegakan Penyusun Hutan Rakyat}

Tegakan jati emas berbeda nyata dalam penyimpanan cadangan karbon yang terdapat pada (Tabel 3). Hal ini dikarenakan perbedaan umur tegakan, diameter dan kerapatan tegakan jati emas dibanding jenis tegakan lain yang mempengaruhi dalam penyimpanan cadangan karbon. Jati emas merupakan salah satu jenis vegetasi yang memiliki cadangan karbon paling tinggi dalam lokasi penelitian ini, karena jati emas memiliki kelas umur, diameter, kerapatan, dan memiliki luas lahan yang berbeda di lokasi penelitian tersebut. Setiap terjadi peningkatan umur tegakan maka jumlah karbon dioksida yang diserap dan disimpan oleh tegakan akan semakin meningkat. Perbedaan ini dapat disebabkan oleh adanya perbedaan volume pohon, jumlah pohon dan diameter pohon. Hal ini sesuai dengan pernyataan Natalia et al, (2014) bahwa serapan karbon dipengaruhi oleh biomassa dan apapun yang dapat menyebabkan bertambah dan berkurangnya potensi biomassa akan berpengaruh pula terhadap serapan. 
Jurnal Belantara Vol. 2, No. 2, Agustus 2019 (112-118)

Tabel 3. Pengaruh perlakuan (tiap jenis tegakan) terhadap potensi cadangan karbon

Table 3. The treatment's effects (each type of tree stands) to carbon stock potention

\begin{tabular}{lccc}
\hline Perlakuan & Nama IImiah & $\begin{array}{c}\text { Rata-rata } \\
\text { Cadangan Karbon } \\
\text { (ton/ha) }\end{array}$ & Notasi \\
\hline $\begin{array}{l}\text { Jati Emas } \\
\text { Jabon Putih }\end{array}$ & $\begin{array}{c}\text { (Tectona grandis) } \\
\text { macropylla) }\end{array}$ & 135.97 & $\mathrm{a}$ \\
$\begin{array}{l}\text { Akasia } \\
\text { Jabon Merah }\end{array}$ & (Acacia mangium) & 59.51 & $\mathrm{~b}$ \\
cadamba) & (Anthosepalus & 54.13 & $\mathrm{~b}$ \\
Jati Putih & (Tectona grandis) & 51.20 & $\mathrm{~b}$ \\
\hline
\end{tabular}

Nilai Uji BNT 5\%

24.14

Keterangan :

a : Beda Nyata

b : Tidak Berbeda Nyata

Hutan memiliki fungsi penting salah satunya yaitu menyerap $\mathrm{CO}_{2}$ di atmosfer. Penyerapan $\mathrm{CO}_{2}$ oleh hutan dilakukan melalui proses fotosintesis yang dilakukan oleh tumbuhan di dalam hutan tersebut. Potensi penyerapan $\mathrm{CO}_{2}$ di hutan rakyat Desa Negara Ratu II pada setiap tipe hutan atau jenis tegakan antara 164.63 hingga 499.00 ton/ha dengan ratarata mencapai 252,22 ton/ha. Jati emas merupakan tegakan yang memiliki jumlah serapan karbon yang nyata berbeda atau lebih tinggi dibandingkan tegakan yang lain, sedangkan empat tegakan yang lain memiliki jumlah serapan karbon yang tidak berbeda. Diameter merupakan indikator besaran jumlah serapan karbon (Putri \& Wulandari, 2011). Studi penelitian yang dilakukan oleh Bhaskara (2017) besarnya penyerapan $\mathrm{CO}_{2}$ di repong damar disebabkan karena vegetasi yang tumbuh memiliki diameter yang besar berkisar 20-108 cm, sedangkan Desa Negara Ratu II hanya memiliki tegakan yang berdiameter rata-rata $20-38.85 \mathrm{~cm}$.

Tabel 3. Pengaruh perlakuan (tiap jenis tegakan) terhadap jumlah serapan karbon Table 3. The treatment's effects (each type of tree stands) to amount of carbon uptake.

\begin{tabular}{ccccc}
\hline NO & Jenis Tanaman & Nama IImiah & $\begin{array}{c}\text { Potensi Penyerapan } \\
\mathbf{C O}_{\mathbf{2}} \text { (ton/ha) }\end{array}$ & Notasi \\
\hline 1 & & (Tectona grandis) & 499.00 & $\mathrm{a}$ \\
2 & Jati Emas & (Anthosepalus macropylla) & 218.40 & $\mathrm{~b}$ \\
3 & Jabon Putih & (Acacia mangium) & 191.20 & $\mathrm{~b}$ \\
4 & Akasia & (Anthosepalus cadamba) & 187.90 & $\mathrm{~b}$ \\
5 & Jabon Merah & (Tectona grandis) & 164.63 & $\mathrm{~b}$ \\
\hline Jumlah & Jati Putih & & 1261.13 & \\
\hline Rata-rata & & & 252.22 & \\
\hline
\end{tabular}

Keterangan :

a : Beda Nyata

b : Tidak Berbeda Nyata

\section{KESIMPULAN}

Hutan rakyat di Desa Negara Ratu II dengan tegakan jati emas memiliki cadangan dan serapan karbon (135,87 ton/ha dan 499,00 ton/ha) paling nyata tertinggi dibandingkan dengan hutan rakyat dengan tipe tegakan lain. Sedangkan nilai cadangan dan serapan karbon antara 
Jurnal Belantara Vol. 2, No. 2, Agustus 2019 (112-118)

jati putih (44,86 ton/ha dan 164,63 ton/ha), akasia (54,13 ton/ha dan 191,20 ton/ha), jabon merah $(51,20$ ton/ha dan 187,90 ton/ha), jabon putih $(59,51$ ton/ha dan 218,40 ton/ha). Tegakan jati emas memiliki cadangan dan serapan karbon lebih tinggi dibandingkan dengan tipe hutan yang lain, sedangkan tipe hutan jati putih, akasia, jabon merah dan jabon putih memiliki cadangan dan serapan karbon yang sama besar

\section{DAFTAR PUSTAKA}

Bhaskara, D.R. (2017). Karbon Tersimpan pada Repong Damar Pekon Pahmungan Kecamatan Pesisir Tengah Kabupaten Pesisir Barat. Skripsi. Lampung: Universitas Lampung.

Brown, S. (1997). Estimating Biomass and Biomass Change of Tropical Forest, A Primer. Rome: FAO Forestry Paper 134.

[BSN] Badan Standarisasi Nasional. (2011). Pengukuran \& Perhitungan Cadangan Karbon. Pengukuran Lapangan untuk Penaksiran Cadangan Karbon Hutan (Ground Based Forest Carbon Accounting). Jakarta: Badan Standarisasi Nasional.

Dinas Kehutanan Provinsi Lampung. (2013). Rencana Pengelolaan Hutan Jangka Panjang Kesatuan Pengelolaan Hutan Lindung (KPHL) Batutegi 2014-2023. Lampung.

Hardjana, A.K. (2010). Potensi biomassa dan karbonpada hutan tanaman acacia mangium di HTI PT. Surya Hutani Jaya, Kalimantan Timur. Jurnal Penelitian Sosial dan Ekonomi Kehutanan. 7 (1): 237-249

Hanafiah, K.A. (2011). Rancangan Percobaan. Jakarta: Rajawali Press.

Hairiah, K. \& Subekti, R. (2007). Pengukuran Karbon Tersimpan di Berbagai Penggunaan Lahan. Bogor: World Agroforestry Center-ICRAF.

[IPCC] Intergovernmental Panel on Climate Change. (2006). Intergovernmental Panel on Climate Change Guidelones for National Greenhouse Gas Inventories. Kanagawa: IGES.

Kaskoyo, H., Mohammed, A.J., dan Inoue, M. (2017). Impact of community forest program in protection forest on livehood outcomes: A case study of Lampung Province, Indonesia.

Natalia, D., Yuwono, S.B. \& Qurniati, R. (2014). Potensi penyerapan karbon pada sistem agroforestri di Desa Pesawaran Indah Kecamatan Padang Cermin Kabupaten Pesawaran Provinsi Lampung. Jurnal Sylva Lestari. 2(1), 11-20.

Nugroho, D. (2014). Menghitung Cadangan Karbon di Hutan Rakyat Panduan bagi Para Pendamping Petani Hutan Rakyat. Yogyakarta: Biro Penerbit ARuPA.

Putri, A.H.M. \& Wulandari, C. (2015). Potensi penyerapan karbon pada tegakan damar mata kucing (Shorea javanica) di Pekon Gunung Kemala Krui Lampung Barat. Jurnal Sylva Lestari, 3(2), 13-20.

Rochmayanto, Y. (2012). Peran Hutan Rakyat dalam Mitigasi Perubahan Iklim Sektor Kehutanan. Semarang: Pusat Penelitian dan Pengembangan Perubahan Iklim dan Kebiijakan.

Tim Arupa. (2014). Menghitung Cadangan Karbon di Hutan Rakyat Panduan bagi Para Pendamping Petani Hutan Rakyat. Sleman: Biro Penerbit Arupa. 